\title{
Public perceptions and factors affecting domestic marine fish consumption in Namibia, southwestern Africa
}

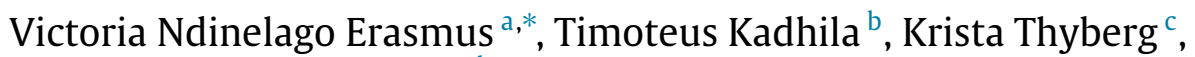 \\ Elizabeth Ngololo Kamara ${ }^{\mathrm{d}}$, Graca Bauleth-D'Almeida ${ }^{\mathrm{e}}$ \\ ${ }^{\text {a }}$ Fisheries Observer Agency, 1st Street East, P O Box 2903, Walvis Bay, Namibia \\ ${ }^{\mathrm{b}}$ National Marine Information and Research Centre (NatMIRC), Ministry of Fisheries and Marine Resources, Strand Street, Box \\ 912, Swakopmund, Namibia \\ ${ }^{\mathrm{c}}$ Department of Technology and Society, Stony Brook University, Stony Brook, NY, USA \\ ${ }^{\mathrm{d}}$ Multi-disciplinary Research Centre, University of Namibia, Mandume Ndemufayo Ave, Pionierspark, Windhoek, Namibia \\ ${ }^{\mathrm{e}}$ Ministry of Fisheries and Marine Resources, Conner of Uhland and Goethe Street, Private Bag 13355, Windhoek, Namibia
}

\section{A R T I C L E I N F O}

\section{Article history:}

Received 20 December 2020

Received in revised form 24 June 2021

Accepted 5 July 2021

Available online 7 July 2021

\section{Keywords:}

Fish consumption

Food security

Perception

Survey

Promotion strategies

\begin{abstract}
A B S T R A C T
Using a web-based survey conducted among 2,481 Namibian, aged 18 years or older, the factors and motivations driving individuals' decisions on marine fish consumption, spatial fish consumption, and possible strategies to promote domestic marine fish consumption were explored. Most participants (97.9\%) were aware of the importance of fish in the human diet, with many preferring hake (Merluccius capensis and M. paradoxus) (31.5\%) and Cape horse mackerel (Trachurus capensis) (21.7\%). Most respondents (64.1\%) were poor fish consumers, consuming fish once a week or once a month. Participants claimed that they mostly purchased marine fish from retail fish shops (50.7\%), wholesale fish companies (18.8\%), and the Namibian Fish Consumption Promotion Trust (17.4\%). Factors affecting marine fish affordability in Namibia were explained with a Logit Model, with age, education, gender, monthly income, and region of residence as the explanatory variables. Responses regarding fish affordability were principally driven by age, education, and monthly income $(p<0.05)$. The Khomas region purchased the most marine fish $(60,764.8$ weighted $\mathrm{kg}$ ) in 2019 . There was a consensus across all participants that regular fish consumption is beneficial to human health; however, participants listed affordability and accessibility of marine fish as critical constraints. Results indicate that Namibian marine fish consumption is poor and needs to be promoted. Results suggest ways to stimulate marine fish consumption locally and elsewhere to meet the UN Sustainable Development Goal 2 to end hunger and alleviate malnutrition.
\end{abstract}

(C) 2021 Published by Elsevier B.V.

\section{Introduction}

Protein is one of the principal nutrients essential for human health and it is found in fish and fish products among other protein-rich foods, such as eggs, chicken, and milk. Many fish, especially marine fish, are high in omega-3 fatty acids, which are heart-friendly, and provide a range of health benefits. A nutritious diet is important, and thus it forms part of the Fish and Agricultural Organisation (FAO) definition of food security (FAO, 2020). The association between a fish-rich diet and human health benefits is well recognised (Leek et al., 2000; Sándor et al., 2011; Schonfeldt, 2013; Maciel et al., 2019), especially in infants, young children, and pregnant women. Although there is variation in nutritional profile among various fish species, generally, fish

\footnotetext{
* Corresponding author.

E-mail address: erasmus.victoria@yahoo.com (V.N. Erasmus).
}

is the most important animal-source protein in the human diet (Sándor et al., 2011; Chan et al., 2019).

Malnutrition is on the rise globally. In 2019, about 820 million people globally were estimated to be chronically undernourished in comparison to 777 million in 2015 (FAO et al., 2019). Many African countries, including Namibia, are battling hunger and malnutrition. By 2019, about 20\% of the population in Africa were undernourished (FAO, 2020). Even though Namibia has a large fishing industry, nearly $30 \%$ of the population is food insecure (FAO, 2019) and more than $20 \%$ of the total population were undernourished in 2015 (Bennett et al., 2018). Consuming nutritious food will shrink malnutrition levels, which is the key target for the UN Sustainable Development Goal 2 (zero hunger) (UNDP, 2016). Given the significant role of fish consumption in food and nutrition security, Namibia is ideally in a better position to address malnutrition and hunger because it produces adequate fish to feed its population which was about 2.4 million in 2017 (NSA, 2017). There have been calls in local media to stimulate 
domestic fish consumption in Namibia (e.g., The Namibian, 2019), but domestic fish consumption remains relatively low. The literature on the perception and factors affecting domestic marine fish consumption in Namibia is lacking.

The Namibian fishing industry is recognised worldwide because it has relatively well-managed fisheries (Sumaila et al., 2004; Paterson et al., 2013), and it supplies fish and other seafood products to more than 80 countries including Spain, Portugal, and France (MFMR, 2018, 2019). As such, the Namibian marine fishery is highly commercialised. Namibia ranks third in Africa for capture fish production (MFMR, 2015; (NPC, 2017). Additionally, the Namibian fishing industry is listed among the top four sectors sustaining the country's economy (MFMR, 2018). Although the Namibian fishing industry is categorised into aquaculture fisheries and marine fisheries, most of its fish and fishery products come from the marine fishery (MFMR, 2018; Bronnmann et al., 2020). Globally, fish consumption is remarkably high, especially in countries where it is produced. For instance, in Norway, about $90 \%$ of Norwegian Atlantic herring (Clupea harengus) caught in 2010 was used for human consumption in Norway (FAO, 2012). Local fish consumption in Namibia is low, despite several initiatives to promote it. Chiripanhura and Teweldemedhin (2016) reported it at $12 \mathrm{~kg}$ per capita per year in 2006 (NPC, 2008). Initiatives to increase domestic fish consumption include the establishment of the Namibia Fish Consumption Promotion Trust (NFCPT) in 2001 (Musaba and Namukwambi, 2011; Paterson et al., 2013) to ensure fish affordability and accessibility. NFCPT has fish shops in 13 of the 14 regions in Namibia (NFCPT, 2019). Additionally, in 2010, the Namibia Alliance for Improved Nutrition (NAFIN) was launched to alleviate chronic malnutrition in the country. Despite these interventions, malnutrition remains deep-rooted in Namibia (MOHSS and ICF International, 2014).

While the importance of fish consumption is clear, studies on fish consumption in Namibia are limited but common in other countries such as Bangladesh (Haque et al., 2019), Bulgaria (Stancheva, 2018) and Nigeria (Adeniyi et al., 2012). The only available study on fish consumption in Namibia (Musaba and Namukwambi, 2011) identified socio-economic factors as the key determinants of consumer fish purchase in Windhoek. Our study differs from the previous one (which only focused on three fish species: Cape horse mackerel Trachurus capensis, hake Merluccius capensis and M. paradoxus, and snoek Thyrsites atun) in that it focuses on all types of marine fish, factors driving domestic marine fish consumption, and the data were collected across Namibia. The objectives of this study were therefore to: (i) establish an understanding of the Namibian community's perception of domestic marine fish consumption; (ii) explore the knowledge of the importance of fish consumption to the human diet; (iii) quantify spatial domestic fish consumption in Namibia in 2019; and (iv) identify factors influencing domestic marine fish consumption and discuss practical methods to boost domestic marine fish consumption. Information on domestic marine fish consumption can be used as a tool to guide policymaking. Results can identify the social, economic, and environmental factors that determine fish consumption, can help find the 'hotspots' where interventions should be prioritised, and thus be instrumental in promoting domestic marine fish consumption across the country.

\section{Materials and methods}

\subsection{Study area}

This study was carried out in Namibia, a country in southern Africa with a total area of $823,290 \mathrm{~km}^{2}$ (UNSD, 2019) and a coastline of $1,572 \mathrm{~km}$. Namibia is a maritime state located between $17^{\circ} 12^{\prime} \mathrm{S}$ and $29^{\circ} 30^{\prime} \mathrm{S}$, where it is bounded in the west by the Atlantic Ocean. Namibia is partitioned into 14 administrative regions: Erongo, Hardap, Kavango East, Kavango West, !Karas, Khomas, Kunene, Ohangwena, Omaheke, Omusati, Oshana, Oshikoto, Otjozondjupa and Zambezi (Fig. 1). With a population of 2.4 million in 2016 (NSA, 2017), Namibia is one of the least densely populated countries in the world, with 3.13 people per square kilometre (NSA, 2017). The Namibia Gini index, a representation of economic inequality was measured at $59 \%$ in 2018 (UNDP, 2019). The unemployment rate was 33.4\% in 2018 (Trading Economics, 2019). In 2017, only $20.5 \%$ of the population had access to the internet (NSA, 2017).

\subsection{Data collection}

The primary data were collected using a web-based survey (using Google Form tool) to better understand fish consumption in Namibia. This was a voluntary survey that used an unrestricted sampling method where anyone could complete the questionnaire. The survey had limited representativeness, particularly those from vulnerable groups (e.g., those that have no access to the internet) (Cohen et al., 2007). The survey targeted adults aged 18 years or older residing in Namibia in 2020. The study defined four age classes: (i) 18-29, (ii) 30-40, (iii) 4160 , and (iv) 60+. Five levels of education were considered: (i) never schooled, (ii) Grades 1-7, (iii) Grades 8-12, (iv) Certificate, and (v) Diploma or higher. Based on the responses, participants were classified into four fish consuming classes: (i) non-fish consumers, (ii) poor fish consumers, (iii) moderate fish consumers, and (iv) regular fish consumers. Secondary data on regional marine fish purchases were sourced from the NFCPT to quantify spatial fish purchase in Namibia in 2019.

A web-based survey was used because this was a nationwide survey where a face-to-face or telephone survey was not possible to meet the study objectives. Web-based surveys are inexpensive, yield quick responses in a short period (Nagalakhmi and Trivedi, 2015; Regmi et al., 2016), and are suitable when face-to-face surveys are not possible (Nagalakhmi and Trivedi, 2015; Regmi et al., 2016). A hyperlink that allowed participants to access the Google Form survey was advertised on Facebook, LinkedIn, WhatsApp, and email groups. Participants had a month (24 June24 July 2020) to complete the survey. To maximise the number of respondents, a contact person from each region was identified and asked to share the survey link on other email groups in their respective regions. Participation in this survey was limited to Namibians with access to the internet. No incentive to encourage participation in the survey was given to the participants.

\subsection{Questionnaire design}

The survey was conducted in English, the sole official language in Namibia since 1990. Although few Namibians (2\%) use English as their first language (Central Bureau of Statistics, 2001), the national English literacy figures (which covers basic education) have increased from $65 \%$ in 1991 to $81.3 \%$ in 2001, while the total youth literacy rate rose to $92 \%$ during 1995 to 2004 , and the adult literacy rate rose to $85 \%$ during the same period (Hanemann, 2017). Therefore, it was acceptable to design the questionnaire in English.

The survey contained 18 questions organised into three sections: the first section asked demographic information (e.g., age, gender, and education level), the second section had questions on fish consumption (e.g., the weekly fish consumed by participants), and the last section focused on the participants' perception of the affordability and accessibility of Namibian marine fish. Some questions from section two and three consisted of Likert-scaled statements used to record responses in a perception set (Burton 


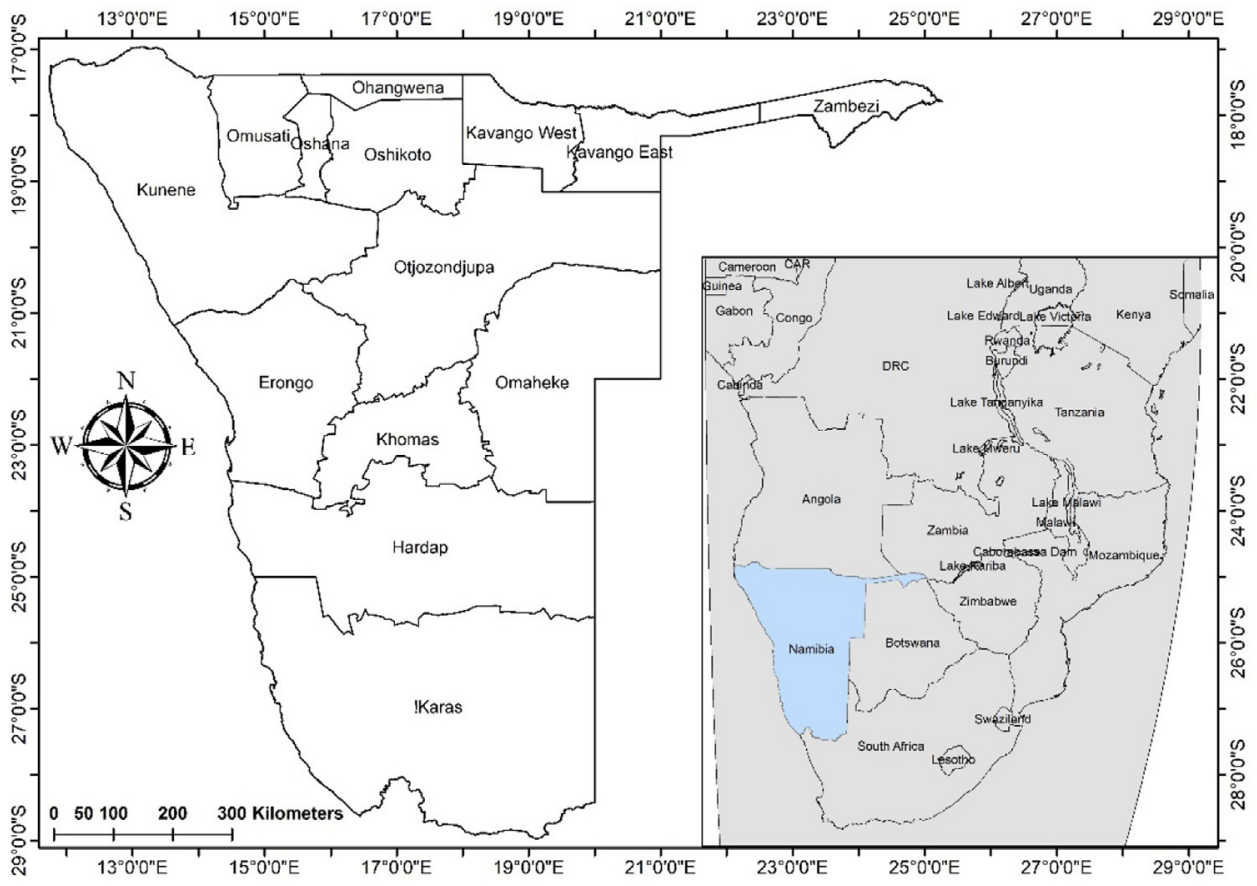

Fig. 1. Namibia and its 14 administrative regions where the survey was conducted from June to July 2020 .

et al., 1998). To ensure the anonymity of participants, no personal information such as name or Identification Number was collected. The questionnaire was preceded by informed consent and participants had a choice to agree or decline to participate. The survey completion time was estimated at six minutes on average. All questions contained in the questionnaire were compulsory. The questions were pilot-tested on 14 participants to make appropriate changes before the commencement of the survey (Verbeke et al., 2007).

\subsection{Data analyses}

A total of 2481 adults nationwide participated in the survey. The primary data collected through this web-based survey were automatically stored in a Google Form spreadsheet and downloaded as a .csv file. The Google Form tool performed basic descriptive statistics such as percentage, mean and frequencies. A comprehensive data analysis was also performed to meet the study objectives. Answers provided in open fields (e.g., fish names) were proofread to guarantee consistent spelling.

To explore the knowledge of the importance of fish in the human diet, we presented the proportions of the respondents who thought fish is important in the human diet, against those who disagreed, in relation to their educational level. Pearson's Chisquared test was used to test for significant differences among the education level with regards to the knowledge of the importance of fish in the human diet.

To establish the level of marine fish consumption in Namibia, participants were asked to state their weekly frequency of fish consumption and were classified into four categories depending on the frequency of consumption. Those who never consumed fish were classified as non-fish consumers, those who consumed fish once a week were classified as poor fish consumers, those who consumed fish two to three times a week were classified as moderate fish consumers, and those who consumed fish four or more times a week were classified as regular fish consumers. To assess significant differences among the four fish consumer classes, Pearson's Chi-squared test was performed. Furthermore, current age, education level, gender, monthly income, and region of residence of survey participants were used as explanatory variables in a Logit model to explain marine fish affordability. Logit models have been extensively applied in fish consumption studies (Musaba and Namukwambi, 2011; Onurlubas, 2013).

All statistical analyses were performed using $\mathrm{R}$ version 3.3.1 software (R Core Team, 2016, http://www.r-project.org/). Differences and associations were considered statistically significant at $\mathrm{p}<0.05$. To quantify spatial domestic fish consumption in Namibia in 2019, we obtained marine fish purchase data per region from NFCPT database. The population is not homogeneously distributed across Namibia, e.g., the majority (52.1\%) of the Namibian population lives in rural areas (NSA, 2017). To enable a comparison of fish purchase per region, the fish purchase per region needed to be weighted by the population in each region as per the 2016 national census (NSA, 2017). ArcGIS was used to map the regional consumption of fish in Namibia. The participants' suggestions of actions to be taken to promote fish consumption in Namibia were used in the recommendations on the way forward in establishing practical methods to boost domestic marine fish consumption.

\section{Results}

\subsection{Demographic data of participants}

A total of 2481 respondents completed the survey. The demographic characteristics of the survey participants show that most participants were from the Erongo region (36.7\%) which is a coastal town, followed by Khomas (31.7\%). Participants were predominantly $30-40$ years old (46.4\%), mostly females $(58.4 \%)$, and earned a total monthly income of more than $\mathrm{N} \$ 10000$ (49.3\%). A large fraction of the participants had a diploma or higher education level (69.1\%) (Table 1).

\subsection{General awareness about the importance of fish in the human} diet

Most participants (97.9\%) agreed that marine fish is important in the human diet. Considering the level of education, most respondents who did not seem to know the importance of including 
Table 1

Demographic characteristics of the survey participants (\% of respondents, $\mathrm{n}=2481)$.

\begin{tabular}{|c|c|c|}
\hline & Variables & Percentage \\
\hline \multirow{3}{*}{ Gender } & Female & 58.4 \\
\hline & Male & 41.5 \\
\hline & LBGT & 0.1 \\
\hline \multirow{4}{*}{ Age group (years) } & $18-29$ & 33.9 \\
\hline & $30-40$ & 46.4 \\
\hline & $41-60$ & 18.7 \\
\hline & +60 & 1 \\
\hline \multirow{5}{*}{ Level of education } & Never schooled & 0.3 \\
\hline & Grade $1-7$ & 0.3 \\
\hline & Grade $8-12$ & 18.4 \\
\hline & Certificate & 11.9 \\
\hline & Diploma or higher & 69.1 \\
\hline \multirow{5}{*}{ Total monthly income (N\$) } & $<500$ & 16.6 \\
\hline & $500-1000$ & 6.8 \\
\hline & $1001-4000$ & 9.8 \\
\hline & $4001-10000$ & 17.5 \\
\hline & $>10000$ & 49.3 \\
\hline \multirow{14}{*}{ Regions in Namibia } & Erongo & 34.4 \\
\hline & Hardap & 0.5 \\
\hline & Kavango East & 1.0 \\
\hline & Kavango West & 0.7 \\
\hline & Khomas & 31.7 \\
\hline & Kunene & 0.8 \\
\hline & Ohangwena & 6.2 \\
\hline & Omaheke & 0.3 \\
\hline & Omusati & 4.3 \\
\hline & Oshana & 7.8 \\
\hline & Oshikoto & 4.2 \\
\hline & Otjozondjupa & 2.9 \\
\hline & Zambezi & 1.1 \\
\hline & !Karas & 3.9 \\
\hline
\end{tabular}

fish in the human diet were those with a primary education level (Grade 1-7) (Fig. 2). Based on Pearson's Chi-squared test, there was a significant difference among the education level with regards to the knowledge of the importance of fish in the human diet $(\mathrm{X}$-squared $=87.31$, df $=8, \mathrm{p}<0.05)$.

\subsection{The most preferred marine fish species}

To determine the most preferred marine fish species, out of 2481 responses only 2368 responses were considered because some fish species listed included freshwater fish species (e.g., Tilapia Oreochromis mossambicus) were excluded from the data analysed. Additionally, some species mentioned were not fish (e.g., squid). Out of the 17 marine fish species ( 8 were listed on the questionnaire while 9 were added by the participants) consumers mostly favoured hake (Merluccius capensis and $M$. paradoxus) (31.5\%), followed by Cape horse mackerel (Trachurus capensis) (21.7\%). Some participants (4.5\%) did not know the name of the fish that they preferred (Fig. 3).

\subsection{Frequency of domestic marine fish consumption}

The respondents were asked how often they consume marine fish on average per week. A total of 55 (2.3\%) responses were not discernible, while $2.6 \%$ of the participants did not respond. Out of a total of 1,951 responses considered, most respondents (64.1\%) were poor fish consumers consuming fish once a week or once a month (Fig. 3). The Chi-square test found a significant variation in the different fish consumer classes (X-squared $=61.20, \mathrm{df}=3$, $\mathrm{p}<0.05$ ).

Participants claimed that they purchased most of the marine fish from the retail fish shops (50.7\%), wholesale fish companies
(18.8\%), NFCPT $(17.4 \%)$, open markets $(10.4 \%)$ and from other various markets $(<2 \%$ each).

Furthermore, participants were questioned on their awareness of NFCPT as the sole institute mandated to promote the consumption of fish in Namibia and to ensure affordability and accessibility of fish countrywide. A total of $73.8 \%$ of participants claimed that they were aware of the existence of NFCPT. The regional analysis showed that the Kavango West and Oshana regions had the highest proportion of consumers who were aware of NFCPT at $88.2 \%$ and $83.9 \%$ respectively, while Omaheke had the least (42.9\%) number (Fig. 5).

3.5. Distribution of marine fish purchase ( $\mathrm{kg}$ ), population distribution and weighted fish purchase by region in 2019

In total $1461140.32 \mathrm{~kg}$ of marine fish was purchased in 2019 (as per the secondary data supplied by NFCPT). Marine fish consumption (measured by the total quantity of fish purchased in kilogrammes [kg]) varied significantly across the 14 Namibian regions in 2019. Most marine fish were purchased in the Khomas region $(60,764.8$ weighted $\mathrm{kg}$ ), and the lowest in the Otjozondjupa region (592.4 weighted $\mathrm{kg}$ ) (Table 2).

3.6. Determinants of domestic marine fish consumption and practical methods to promote marine fish consumption in Namibia

Survey results indicate that marine fish consumption in Namibian is poor (Fig. 4). Out of the factors listed by the participants, the key constraints of domestic marine fish consumption are affordability and accessibility. On affordability, $60.5 \%$ of participants claimed that fish is not affordable which may be a causal factor for poor consumption. On accessibility, $61.3 \%$ of the participants stated that fish is not readily accessible when they need it. Other participants did not consume fish for health or cultural reasons. Some consumers were not confident in preparing fish meals and some did not prefer fish.

\subsection{Logit model}

Based on the Logit Model applied to the data collected from 2,149 participants, the modelling results reveal that for the participants to respond that fish is affordable or not, their responses were principally driven by age, education level and monthly income of participants $(\mathrm{p}<0.05)$, while the region of residence did not significantly influence this response $(p>0.05)$ (Table 3$)$.

\subsection{Proposed strategies to promote domestic marine fish consump-} tion

Survey questions were asked to better understand factors that could promote fish consumption in Namibia. A total of $49.7 \%$ of participants suggested a reduction in the current fish price would lead to higher fish consumption. $39.2 \%$ of the participants suggested an increase in local marine fish supply nationwide including remote areas would help. $11.1 \%$ were in favour of the introduction of fish consumption awareness campaigns to boost local marine fish consumption.

\section{Discussion}

\subsection{Survey respondents}

The survey received a relatively high response rate (2481 respondents) compared to other similar surveys (Hicks et al., 2008; Cardoso et al., 2013). The survey had a high participation rate $(46.4 \%)$ from the $30-40$ age group, likely due to their high 


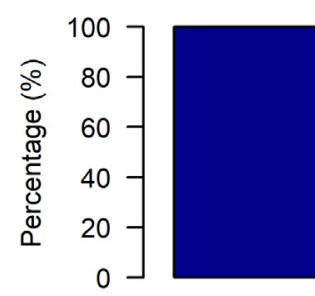

Never schooled

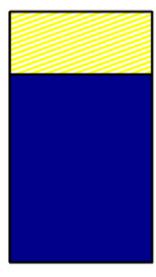

Gr1-7

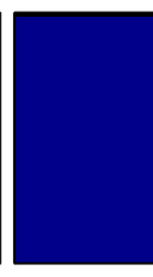

Gr8-12

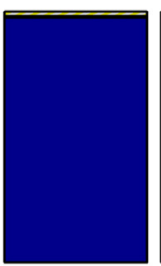

Certificate Diploma/higher

*Gr 1-7 = Grade 1-7, Gr8-12 = Grade 8-12

Fig. 2. Awareness of the importance of fish in the human diet, as per the response of the survey participants.

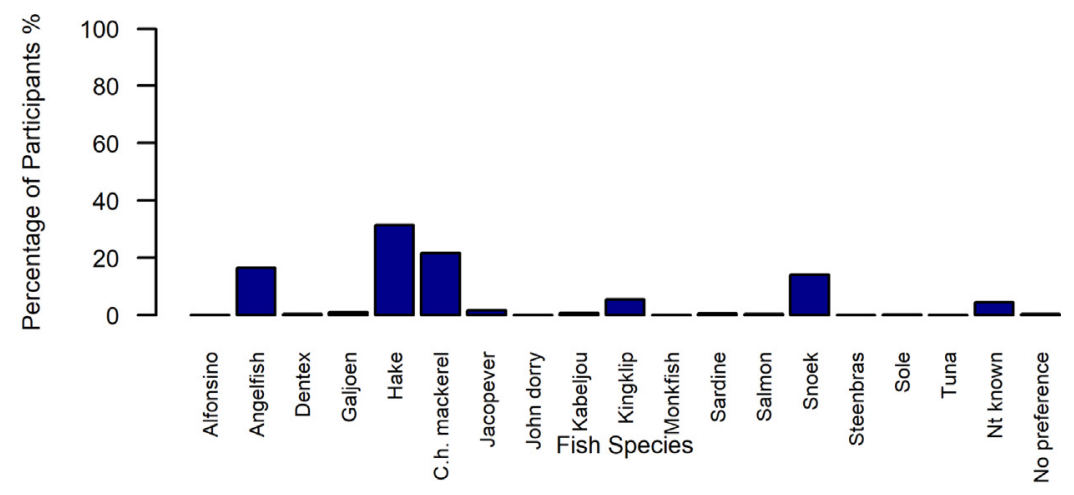

*C.h. mackerel $=$ Cape horse mackerel, Nt known $=$ name not known

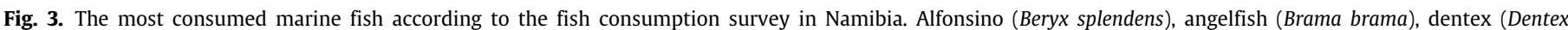

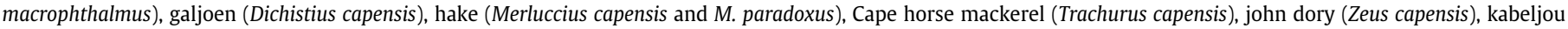

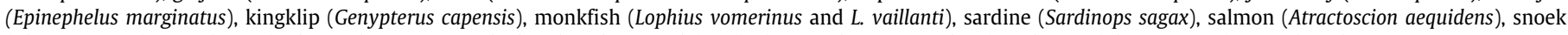
(Thyrsites atun), steenbrass (Lithognathus aureti, and Chirodactylus grandis), sole (Austroglossus microlepis) and tuna (Thunnus spp.) were listed.

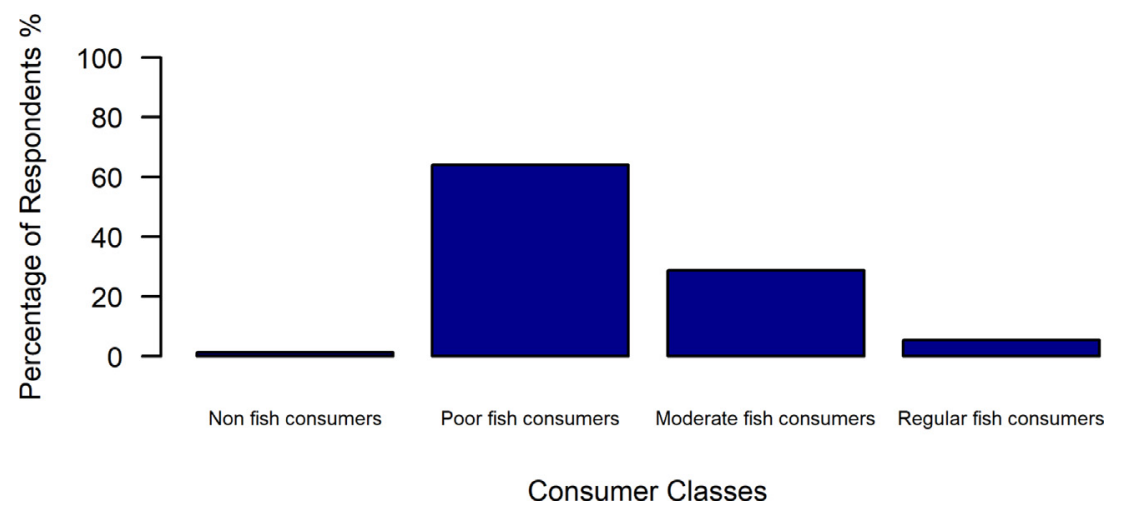

Fig. 4. The frequency of domestic marine fish consumption in Namibia based on the response of the survey participants.

technology affinity. Elderly participants were underrepresented (1\%), probably owing to their difficulties in the use of electronic devices and internet resources (Table 1). Most participants were residents of the Erongo region, the region with the most fishing processing facilities and the largest sea-port in Namibia (Erasmus et al., 2021). This puts the residents in a better position to develop an interest in fishery-related discussions. Most respondents were females (58.4\%), as also in the previous study (78\%) on fish consumption in Namibia (Musaba and Namukwambi, 2011). This reflects the Namibian population structure which is skewed towards females (NSA, 2017). The high proportion of female respondents could also be reflective of who makes dietary decisions within Namibian households. The main limitation of our study remains that conclusions are derived from a proportion of participants who had access to the internet and not necessarily representative of the entire Namibian population. This limitation could affect values, attitudes, norms, and consumer behaviour that were observed, and thus warrant further studies.

Most participants (97.9\%) agreed that fish is important in a human diet. Considering the level of education, most respondents who did not seem to know the importance of including fish in the human diet were those with a primary education level (Grades 1-7) (Fig. 2). This might suggest an association between an understanding of dietary needs with education level (Maciel et al., 2019). A large fraction of the participants had a diploma or higher education level (69.1\%). This group of people are aware of 


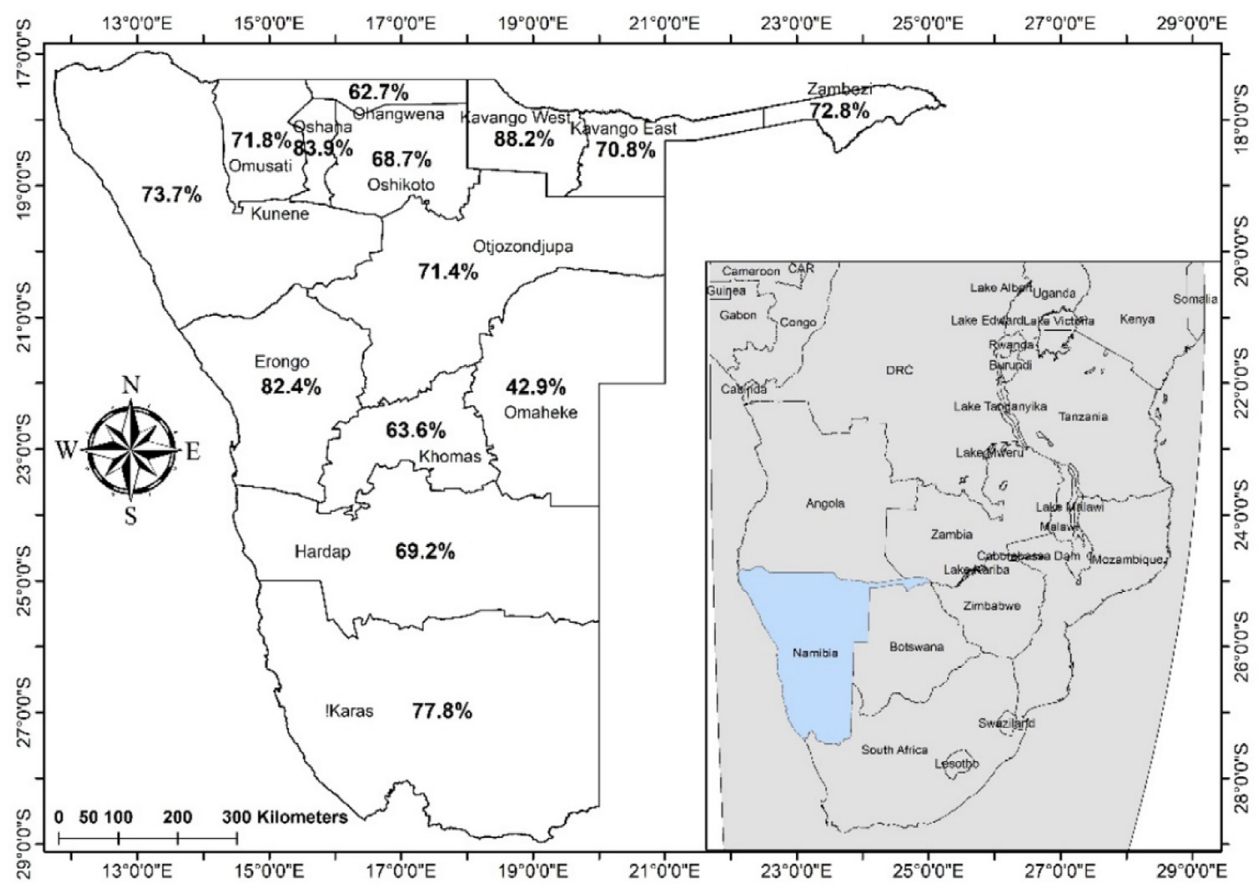

Fig. 5. Percentage response of the participants' awareness of the Namibia Fish Consumption Promotion Trust (NFCPT).

Table 2

Spatial purchase of marine fish across 14 regions of Namibia in 2019 (data courtesy of Namibian Fish Consumption Promotion Trust).

\begin{tabular}{|c|c|c|c|c|}
\hline Region & $\begin{array}{l}\text { Fish purchased in } \\
2019 \mathrm{~kg}\end{array}$ & $\begin{array}{l}\text { Total population in } \\
2016\end{array}$ & Population\% & Weighted $\mathrm{kg}$ \\
\hline Total purchase & 1461140.32 & & & \\
\hline Total population & 2424388 & & & \\
\hline Hardap & $14,485.65$ & 187,186 & 7.7 & $1,118.4$ \\
\hline Kavango East & $101,443.06$ & 148,466 & 6.1 & $62,12.2$ \\
\hline Kavango West & $54,960.55$ & 89,313 & 3.7 & $20,24.7$ \\
\hline Kunene & $23,173.49$ & 97,865 & 4.0 & 935.4 \\
\hline Ohangwena & $136,175.95$ & 255,510 & 10.5 & $14,351.8$ \\
\hline Omaheke & $192,44.47$ & 74,629 & 3.1 & 592.4 \\
\hline Omusati & $137,633.85$ & 249,885 & 10.3 & $14,186.1$ \\
\hline Oshana & $308,605.28$ & 189,237 & 7.8 & $24,088.4$ \\
\hline Oshikoto & $86,603.9$ & 195,165 & 8.1 & $6,971.7$ \\
\hline
\end{tabular}

Table 3

The results of the Logit model of the survey participants (\% of respondents, $n=2149$ ).

\begin{tabular}{lllcl}
\hline & Estimate & Standard error & Z-value & $p$-value \\
\hline Age & $-2.845 \mathrm{e}-02$ & $5.893 \mathrm{e}-03$ & -4.828 & $1.38 \mathrm{e}-06$ \\
Education level & $-1.461 \mathrm{e}-01$ & $4.347 \mathrm{e}-02$ & -3.362 & 0.000774 \\
Monthly income & $-5.101 \mathrm{e}-05$ & $1.148 \mathrm{e}-05$ & -4.445 & $8.80 \mathrm{e}-06$ \\
Region of residence & $3.461 \mathrm{e}-03$ & $1.199 \mathrm{e}-02$ & 0.289 & 0.772815 \\
\hline
\end{tabular}

dietary needs and are often interested in national conversations on various platforms. A high education level also may suggest a good income that can afford the participant access to the internet.

\subsection{Fish preferences and consumption frequency}

Most respondents preferred hake and Cape horse mackerel despite many other fish species harvested off Namibia. Hake and Cape horse mackerel are the marine fish sold in the highest quantity in comparison to other fish species in the NFCPT fish shops (The Namibian, 26 February 2019). In a study on socio-economic determinants of consumer fish purchase in Windhoek (Musaba and Namukwambi, 2011), it was found that the likelihood to purchase hake was higher among high-income households than in low-income households, affirming the issues of affordability. A large percentage of our survey participants (49.3\%) earned a monthly salary of more than $N \$ 10000$, which might have influenced their choice of hake. Cape horse mackerel, the second most preferred marine fish species, is relatively inexpensive, readily available and is the highest species in Namibia in terms of landed volume (Kirchner et al., 2010; Kainge et al., 2020). The fish preferences were most likely influenced by affordability, the accessibility of particular fish species and the fish texture (Verbeke et al., 2007). 
Most respondents (64.1\%) were poor fish consumers, consuming fish once a week or once a month. This is lower than the recommended two to three servings of fish (preferably oil fish) per week (Schonfeldt, 2013; USDA, 2015). Namibia produces a large amount of capture fish, ranked third in Africa in 2017 (NPC, 2017 ) but fish consumption remains low based on our survey and as per NFCPT (The Namibian, 2019). This is paradoxical, especially since many participants (97.9\%) were aware of the importance of fish in the human diet.

Although Namibia has a coastline of about 1572 km, Namibia's population density is mostly inland (NSA, 2017). Scarce settlement along the coast is attributed to the inhospitable nature of most coast due to the harsh environmental conditions, as well as restricted access due to national park protection or diamond mining concessions (Kainge et al., 2020). This differs from other coastal countries, such as Angola and South Africa, where the coastal areas are densely populated (Sauer et al., 2003; Neto, 2015). As such a majority of the population lives far from the sea-ports where marine fish is more available and accessible. The traditional diet in Namibia is red meat-based and heavily relies on carbohydrates from maize and mahangu porridge that is customary in most African countries (FAO, 2017). Furthermore, more than $20 \%$ of the Namibian total population was undernourished in 2015 (Bennett et al., 2018) and malnutrition remains a significant underlying cause of death in children below the age of five in Namibia (WHO, 2014). Regular fish consumption can help mitigate these malnutrition issues (UNSD, 2019). Recent predictions foresee an increase in the per capita fish consumption globally, except in Africa (OECD/FAO, 2017)). The lack of an increase in fish consumption in Africa is projected to aggravate the malnutrition status as fish provides valuable micronutrients and protein. More effort should be directed at persuading Namibians to regularly consume fish. Efforts focusing on food security and nutrition should recognise the potential of fish in providing essential micronutrients to improve the dietary quality, nutritional status, and human well-being (Chan et al., 2019).

\subsection{Marine fish purchase}

Results showed that there is a clear preference for purchasing marine fish from retail fish shops (50.7\%) and wholesale fish companies (18.8\%). This is likely driven by fish prices at these markets. NFCPT is the sole organisation tasked to promote fish consumption in Namibia by ensuring affordability and accessibility (Musaba and Namukwambi, 2011; Paterson et al., 2013). Although $73.8 \%$ of the participants claimed that they were aware of the NFCPT, only $17.4 \%$ of participants purchased marine fish from this trust. It remains to be investigated why so few participants purchased marine fish from NFCPT. Since some regions have fewer NFCPT fish outlets than others, there is unequal accessibility of fish sold by NFCPT (NFCPT, 2019). It is also possible that the prices of fish were not affordable even at the NFCPT fish outlets.

NFCPT is well known among the survey participants (73.8\%). However, regional analyses show that the Kavango West and Oshana regions had the highest proportion of consumers who were aware of this trust ( $88.2 \%$ and $83.9 \%$ respectively), which possibly reflects good marketing strategies in these regions. The current effort by NFCPT focused on promoting fish consumption in Namibia needs to be intensified, especially in the Omaheke region where only $42.9 \%$ of the participants were aware of NFCPT.

\subsection{Accessibility and consumption drivers}

Why does the high fish production in Namibia does not equal a high fish consumption? To understand the determinant factors in fish consumption, participants were asked to give reasons that restrict regular fish consumption. The most important factors influencing domestic fish consumption were affordability, accessibility, health reasons, cultural values, and fish taste. Although marine fish species have different prices depending on the type of fish species and size, most participants indicated that fish was not affordable in Namibia even though most (49.3\%) earned over N\$10 000 monthly. Some marine fish species, such as monkfish (Lophius vomerinus and L. vailanti) were hardly favoured (< $1 \%$ participants), likely because of their high cost. Monkfish is scarcely consumed locally probably because it is a highly valuable fish on global markets (MFMR, 2018; Boyer and Hampton, 2001; Maartens and Booth, 2001). Monkfish is mostly processed at sea (Erasmus et al., 2021) and the products are mostly exported. Namibia shares various fisheries resources (e.g., hake) with Angola and South Africa (the three countries forming the Benguela Current Large Marine Ecosystem) (Sowman and Cardoso, 2010; Kainge et al., 2020). However, based on the (FAO, 2017) report, Namibia exports the most fish (453 $476 \mathrm{t}$ ) in comparison to the other two countries. Kainge et al. (2020) described the marine fisheries in Namibia as almost solely commercial. Thus, the fish prices in Namibia are globalised and linked to international markets (Bronnmann et al., 2020), which consequently influences local fish prices. The mounting price of fish products in Senegal has been noted as a leading cause of food vulnerability (Thiao et al., 2018). Similarly, affordability was also the most obvious constraint to increasing fish consumption in Bulgaria (Stancheva, 2018). The Logit model indicates that age, education level and monthly income of survey participants significantly influenced the perception of marine fish affordability by participants.

Less than $1 \%$ of the participants stated that they did not consume fish because they did not like the fish taste. The issue of fish taste acting as a barrier to fish consumption has also been raised before (Leek et al., 2000; Musaba and Namukwambi, 2011). Few participants $(<1 \%)$ claimed that they did not consume fish because of cultural reasons, bothered by too many fish bones, lack of fish cooking skills and health concerns. A lack of freezers to keep fish fresh, especially in remote areas, is important in fish consumption. A large Namibian population (52.1\%) resides in rural areas (NSA, 2017) where electricity and cooling devices are limited. However, these groups were likely underrepresented in our survey.

Participants were dissatisfied with fish accessibility, with $61.7 \%$ claiming that the fish was not readily accessible. Fish consumption is a complex issue, thus the factors discussed in this study are linked. For instance, limited accessibility of fish in specific regions, especially those farther from the sea-ports (e.g., Kunene), showed its effect on the most preferred fish with these remote regions preferring Cape horse mackerel because they are not exposed to a variety of fish species as participants in the coastal towns (e.g., Erongo). Long distances from the sea-ports to various inland regions and challenging logistics are some of the multiple challenges contributing to the uneven distribution of Namibian marine fish species across the country (Brunsø, 2003; Paterson et al., 2014). NFCPT should ensure that fish is made readily available countrywide. Unaffordability and inaccessibility of marine fish are hindering the call for the public to consume fish regularly.

The secondary data indicate a significant variation in spatial marine fish consumption across Namibia with the Khomas region purchasing the most fish in 2019 (Table 2). This indicates that fish consumption is not homogeneous with geographical region (Swartz and Pauly, 2008). These regional differences can 
be attributed to differences in regional population density, which varies considerably, with Khomas having the highest population density (NSA, 2017). Furthermore, the distance from the seaports is also an important geographical parameter, acting as a determinant of fish consumption as also observed in Portugal (Cardoso et al., 2013). Although regions in proximity of the seaports, such as Erongo and !Karas, enjoy much better availability of fish, their population is low compared to Khomas, and hence these regions with low population have low marine fish purchase, an indication that availability does not necessarily translate into consumption. Although there are 17 NFCPT fish shops across 13 regions of Namibia, with an exception of the Otjozondjupa region, the number of NFCPT fish shops also vary regionally with some regions having two fish shops (e.g., Khomas region) while others have one shop (e.g., Hardap region) (NFCPT, 2019). Regional differences in fish consumption reflect variations in fish affordability, accessibility, availability, cultural food preferences, and social behaviour in Namibia.

\subsection{Promoting fish consumption}

To promote marine fish consumption, several strategies were identified. The first is to reduce the amount of fish exported to other countries. Currently, Namibia exports about 75\% of fish and seafood (MFMR, 2018). This limits the fish species available for domestic consumption, thus compromising the food security of the exporting countries (Swartz and Pauly, 2008). Many African countries export particularly high-value fish to developed countries, which is likely to negatively impact the local populations' food security and livelihoods (Chan et al., 2019).

Where possible, Namibians should be encouraged to fish on an artisanal fishing level, a practice that supports food and nutrition security (FAO, 2015). Unlike other African countries, Namibia has no legally recognised artisanal fishery (Sowman and Cardoso, 2010). The fish products consumed in Senegal are mostly landed by the artisanal fisheries (Thiao et al., 2018). The artisanal fishery is also significant for Angola, which shares some of the marine resources with Namibia (Neto, 2015; Kainge et al., 2020). A Nigerian study (Adeniyi et al., 2012) found 68\% of participants identified as self-employed fishers while in this study, none of the survey participants identified as fishery artisans. Human settlement along the Namibian coast is minimal due to the harsh and arid coastal environment Anon (2010), leading to a poor culture of artisanal fishing. Moreover, the structure of the Namibian fishing sector is simplified by the limited number of ports (only two ports).

Collective efforts from various stakeholders (e.g., government agencies, health workers, fishermen) are needed to produce more food and nutritional awareness campaigns. It would be useful to establish national campaigns, such as "Eat Fish Namibia", similar to the campaigns in developed countries (e.g., the "Eat Seafood, America" campaign). The development of nutritional campaigns has been long suggested to promote low-cost nutritious diets and sustainable food program intervention strategies which can be instrumental in increasing consumer awareness (Mbhenyane et al., 2020). To increase fish consumption, the health benefits of eating fish and other seafood should be better explained as well (Aydin et al., 2011).

\subsection{Limitations}

This study was limited to the participants with access to the internet. Moreover, most participants were graduates and were at a relatively high-income level. Therefore, there is a large sector of the Namibian population that was not captured in this survey, which might have skewed our results. To address this limitation, future work should include the population that was lacking in our survey (e.g., non-educated, those without internet access) and should also translate the survey into various Namibian languages to limit possible language barriers. Despite these drawbacks, our study provides useful insights into the public perception of marine fish consumption across Namibia.

\section{Conclusion}

The study helped us to understand the issues of low fish consumption in Namibia, mainly due to fish scarcity and unaffordability. These findings are important for the implementation of policies that encourage fish consumption and consequent improvement of lifestyle (Trondsen et al., 2003). There was a common and positive perception of most participants (97.9\%) that consuming fish is important for a human diet; however, barriers to fish consumption need to be addressed immediately. This study provides evidence that marine fish consumption and perception vary significantly across Namibia, with the Khomas region purchasing the most fish. This study also provides a muchneeded context to promote local fish consumption. The insights are essential for policymakers and other stakeholders in the fishing industry to formulate and implement strategies to promote fish consumption in Namibia. Results from this study are anticipated to contribute to the promotion of local fish consumption, which is a significant aspect globally. The Namibian fishing industry has the potential to significantly improve domestic marine fish consumption, but not without more effort to address the discussed barriers to domestic fish consumption. Although interventions to promote fish consumption (e.g., NFCPT efforts) exist, additional efforts must be spent to mitigate barriers to local fish consumption. Namibia should enact policies to promote seafood consumption, such as by increasing the affordability of fish. This study builds on existing work to boost domestic fish consumption in Namibia. It also contributes to the ongoing discourse of promoting fish consumption, especially in developing countries. From this study, researchers, health workers, fishing companies, marketers, and other stakeholders can identify which factors influence fish consumption they need to focus on, in line with Namibian consumers' perceptions. Understanding consumers' perception of domestic marine fish consumption is crucial to the success of domestic marine fish consumption in Namibia and elsewhere.

\section{CRediT authorship contribution statement}

Victoria Ndinelago Erasmus: Conceptualization, Survey design, Data analysis, Interpretation of results, Manuscript writing and review. Timoteus Kadhila: Survey design, Data analysis, Interpretation of results, Manuscript writing. Krista Thyberg: Interpretation of results, Manuscript editing and review. Elizabeth Ngololo Kamara: Literature review, Review of survey questions and editing. Graca Bauleth-D'Almeida: Review of survey questions, Editing and advice on data analysis.

\section{Declaration of competing interest}

The authors declare that they have no known competing financial interests or personal relationships that could have appeared to influence the work reported in this paper.

\section{Acknowledgements}

We are thankful to the Namibia Fish Consumption Promotion Trust (NFCPT) for providing us with secondary data. We are especially thankful to Victor Pea of NFCPT and Stanley Ndara for FOA for reviewing several drafts of this paper. A big thank you also to Abner Nghoongoloka who helped with mapping. We also thank all the participants who participated in the survey and further shared the link on various platforms. This research did not receive any financial support. 


\section{References}

Adeniyi, O.R., Omitoyin, S.A., Ojo, O.O., 2012. Socio-economic determinants of consumption pattern of fish among households in Ibadan north local government area of Oyo State, Nigeria. Afr. J. Food Agric. Nutr. Develop. 12.

Aydın, H., Dilek, M.K., Aydın, K., 2011. Trends in fish and fishery products consumption in Turkey. Turk. J. Fish. Aqu. Sci. 11, 499-506, http://dx.doi. org/10.4194/trjfas.2011.0318.

Bennett, A., Patil, P., Kleisner, K., Rader, D., Virdin, J., Basurto, X., 2018. Contribution of Fisheries to food and nutrition security: Current knowledge, policy, and research. In: NI Report 18-02. Duke University, Durham. Durham, NC, http://nicholasinstitute.duke.edu/publication.

Boyer, D.C., Hampton, I., 2001. An overview of the living marine resources of Namibia. South African J. Marine Sci. 23, 5-35.

Bronnmann, J., Smith, M.D., Abbott, J., Hay, C.H., Næsje, T.F., 2020. Integration of a local fish market in namibia with the global seafood trade: Implications for fish traders and sustainability. World Dev. 135, 105048, https://doi.org/ 10.1016/j.worlddev.2020.105048.

Brunsø, K., 2003. Consumer research on fish in Europe. In: Luten, J.B., Oehlenschlaeger, J., Olafsdóttir, G. (Eds.), Quality of Fish from Catch To Consumer - Labelling, Monitoring and Traceability. Wageningen Academic Publishers, Wageningen, The Netherlands., pp. 335-344.

Burton, S., Lichtenstein, D.R., Netemeyer, R.G., Garretson, J.A., 1998. A scale for measuring attitude toward private label products and an examination of its psychological and behavioral correlates. J. Acad. Mark. Sci. 26, 293-306.

Cardoso, C., Lourenço, H., Costa, S., Gonçalves, S., Nunes, M.L., 2013. Survey into the seafood consumption preferences and patterns in the Portuguese population. Gender and regional variability. Appetite 64, 20-31, http://dx. doi.org/10.1016/j.appet.2012.12.022.

Chan, C.Y., Tran, N., Pethiyagoda, S., Crissman, C.C., Sulser, T.B., Phillips, M.J., 2019. Prospects and challenges of fish for food security in Africa. Glob. Food Secur. 20, 17-25, https://doi.org/10.1016/j.gfs.2018.12.002.

Chiripanhura, B., Teweldemedhin, M., 2016. An Analysis of the Fishing Industry in Namibia: The Structure, Performance, Challenges, and Prospects for Growth and Diversification.

Cohen, L., Manion, L., Morrison, K., 2007. Research Methods in Education, 6th ed Routledge, London, pp. 469-470, https://doi.org/10.1111/j.1467-8527.2007. 00388_4.X.

Erasmus, V.N., Kadhila, T., Gabriel, N.N., Thyberg, K.L., Ilungu, S., Machado, T., 2021. Assessment and quantification of Namibian seafood waste production. Ocean Coast. Manage. 199, https://doi.org/10.1016/j.ocecoaman.2020.105402.

FAO, 2012. Food and Agriculture Organisation (FAO), 2012. Food and Agriculture Organization of the United Nations. Feeding the growing aquaculture sector: an analysis. Working document of the FAO COFI Sub-Committee on Aquaculture, Session VI, 26-30 2012, Cape Town, South Africa.

FAO, Food and Agriculture Organisation (FAO), Food and Agriculture Organization of the United Nations, 2015. Voluntary Guidelines for Securing Sustainable Small-Scale Fisheries. Preface. FAO, Rome, (available at http://www.fao.org/ 3/a-i4356en.pdf).

FAO, Food and Agriculture Organisation (FAO), Food and Agriculture Organization of the United Nations, 2017. The State of Food Security and Nutrition in the World: Building Resilience for Peace and Food Security. Food and Agriculture Organization of the United Nations, Rome.

FAO, IFAD, UNICEF, WFP WHO, 2019. The State of Food Security and Nutrition in the World 2019. Safeguarding Against Economic Slowdowns and Downturns. FAO, Rome, p. 235, Licence: CC BY-NC-SA 3.0 IGO. www.fao.org/3/ca5162en/ ca5162en.pdf.

FAO, Food and Agriculture Organisation (FAO), Food and Agriculture Organization of the United Nations, 2019. FAO in Namibia. Available from: https:// www.fao.org/namibia/fao-innamibia/namibia-at-a-glance/en/ (Accessed: 29 September 2020).

FAO, Food and Agriculture Organisation (FAO), 2020. World Food and Agriculture - Statistical Yearbook 2020. FAO, Rome, https://doi.org/10.4060/cb1329.

Hanemann, U. (Ed.), 2017. National Literacy Programme, Namibia. UNESCO Institute for Lifelong Learning, (Accessed on: 9 June 2020, 15:01 CEST).

Haque, Md E., Khanom, S., Afrad, Md. S.I., Barau, A.A., Rafiquzzaman, S.M., 2019. Consumer preference for sea fish consumption in Dhaka City of Bangladesh. Agriculturists 17, 41-51.

Ministry of Health Social Services (MOHSS), Ministry of Health and Social Services and ICF International, 2014. The Namibia Demographic and Health Survey 2013. MoHSS and ICF International, Windhoek, Namibia, and Rockville, Maryland, USA

Hicks, D., Pivarnik, L., McDermott, R., 2008. Consumer perceptions about seafood - an Internet survey. J. Foodserv. http://dx.doi.org/10.1111/j.1745-4506.2008. 00107.x.

Kainge, P., Kirkman, S.P., Estev, V., van der Lingen, C.D., Uanivi, U., Kathena, J.N., van der Plas, A.., Githaiga-Mwicigi, J., Makhado, A., Nghimwatya, L., Endjambi, T., Paulus, S., Kalola, M., Antonio, M., Tjizoo, B., Shikongo, T., Nsiangango, S., Uahengo, T., Bartholomae, C., Mqoqi, M., Hamukuaya, H.,
2020. Fisheries yields, climate change, and ecosystem-based management of the Benguela Current large marine ecosystem. Environ. Develop. https: //doi.org/10.1016/j.envdev.2020.100567.

Kirchner, C., Bauleth-D'Almeida, G., Wilhelm, M.R., 2010. Assessment and management of Cape horse mackerel Trachurus capensis off Namibia based on a fleet-disaggregated age-structured production model. Afr. J. Mar. Sci. 32, 525-541, https://doi.org/10.2989/1814232X.2010.53814.

Leek, S., Maddock, S., Foxall, G., 2000. Situational determinants of fish consumption. Br. Food J. 102, 18-39, . http://dx.doi.org/10.1108/00070700010310614.

Maartens, Lima, Booth, A.J., 2001. Assessment of the monkfish Lophius vomerinus resource off Namibia. South African J. Marine Sci. 23 (1), 275-290. http: //dx.doi.org/10.2989/025776101784528926.

Maciel, E.D., Sonati, J.G., Galvao, J.A., Oetterer, M., 2019. Fish consumption and lifestyle: a cross-sectional study. Food Sci. Technol., Campinas 39, 141-145.

Mbhenyane, X.G., Tambe, B.A., Phooko-Rabodiba, D.A., Nesamvuni, C.N., 2020. Dietary pattern, household hunger, coping strategies and nutritional status of children in Sekhukhune district of Limpopo province, South Africa. Afr. J. Food Agric. Nutr. Develop. 20, 15821-15836. http://dx.doi.org/10.18697/ ajf\{and\}.91.18630.

Ministry of Fisheries Marine Resources (MFMR), 2018. Ministry of Fisheries and Marine Resources Annual Report 2017/2018. (Unpublished Report). Ministry of Fisheries and Marine Resources, The Republic of Namibia, Windhoek.

Ministry of Fisheries Marine Resources (MFMR), 2019. Ministry of Fisheries and Marine Resources. Statistics. Unpublished LandIng Data. Ministry of Fisheries and Marine Resources, The Republic of Namibia, Windhoek.

Musaba, E.C., Namukwambi, M., 2011. Socio-economic determinants of consumer fish purchase in Windhoek, Namibia. Afr. J. Agric. Res. 6, 1483-1488. http: //dx.doi.org/10.5897/AJAR10.429, http://www.academicjournals.org/AJAR.

Nagalakhmi, L.R.A., Trivedi, M.J., 2015. Utilization of online survey tools for academic research: A practical approach to survey monkey. Int. J. Res. Publ. 4

Neto, V.F.L.C.B., 2015. Alguns Aspectos Sócio-Económicos das Pescarias de Peixes Demersais e Pequenos Peixes Pelós de Angola. Imprensa Nacional - EP 127.

NFCPT, Namibia Fish Consumption Promotion Trust (NFCPT, 2019. Annual Report 2008/2019. Namibia Fish Consumption Promotion Trust -Bringing Fish to the Nation, Namibia.

NPC, National Planning Commission (NPC), 2008. Third National Development Plan (NDP3) 2007/08-2011/12 Volume 1. National Planning Commission, Windhoek.

NPC, National Planning Commission (NPC), 2017. Namibia's Fifth National Development Plan (NDP5) - 2017/18-2021/22. National Planning Commission, Windhoek.

NSA, Namibia Statistical Agency (NSA, 2017. Namibia Inter-Censal Demographic Survey 2016 Report. Namibia Statistics Agency, Windhoek.

Onurlubas, E., 2013. The factors affecting fish consumption of the consumers in Kesan Township in Edirne. Bulgarian J. Agricultural Sci. 19.

Organisation for Economic Co-operation Development/Food Agriculture Organization of the United Nations (OECD/FAO), 2017. Fish in seafood. In: OECD-FAO Agricultural Outlook 2017-2026. OECD Publishing, Paris, https: //doi.org/10.1787/agr_outlook-2017-12-en.

Paterson, B., Kirchner, C., Ommer, R.E., 2013. A short history of the namibian hake fishery, a social-ecological analysis. Ecol. Soc. 18.

Paterson, B., Sowman, M., Raemaekers, S., Russel, D., Nkosi, L., Draper, K., Willemse, N., 2014. Strengthening the human dimension of an ecosystem approach to Fisheries management in the BCC region. In: FINAL REPORT of FAO-BCC Project EAF 09/12. Benguela Current Commission, Windhoek, p. 93.

Regmi, P.R., Waithaka, E., Paudyal, A., Simkhada, P., van Teijlingen, E., 2016. Guide to the design and application of online questionnaire surveys. Nepal J. Epidemiol. (4), 640-644.

Sándor, Z., Papp, Z.G., Csengeri, I., Jeney, Z., Fish meat quality and safety. International 56th Meat Industry Conference, Tara, Serbia. pp. 97-105.

Sauer, W.H.H., Hecht, T., Britz, P.J., Mather, D., 2003. An economic and sectoral study of the South African fishing industry. In: Economic and Regulatory Principles, Survey Results, Transformation and Socio-Economic Impact. Department of Environment Affairs and Tourism, Branch Marine and Coastal Management.

Schonfeldt, C.H., 2013. Food-based dietary guidelines for South Africa: Fish, chicken, lean meat and eggs can be eaten daily. S. Afr. J. Clin Nutr. 26 (3(Supplement)), S66-S76.

Sowman, M., Cardoso, P., 2010. Small-scale fisheries and food security strategies in countries in the Benguela Current Large Marine Ecosystem (BCLME) region: Angola, Namibia and South Africa. Mar. Pol. 34 (6), 1163-1170, https://doi.org/10.1016/j.marpol.2010.03.016.

Stancheva, M., 2018. A survey of fish consumption in Bulgaria. In: International Symposium on Animal Science (ISAS). ISBN: 978-86-7834-316-2, Пољопривреда _ Зборници COBISS.SR-ID 270329868.

Sumaila, U.R., Boyer, D., Skogen, M.D., Steinshamn, S.I., 2004. Namibia's fisheries: introduction and overview. In: Sumaila, U.R., Steinshamn, S.I., Skog, M., Boyer, D.C. (Eds.), Ecological, Economic and Social Aspects of Namibian Fisheries. Eburon, Netherlands, pp. 1-9. 
Swartz, W., Pauly, D., 2008. Who's Eating All the Fish? The Food Security Rationale for Culling Cetaceans. Santiago.

The Namibian, 2019. 26 February 2019 https://www.namibian.com.na/public/ uploads/documents/5c890066c07bd/Fishing\%202019.pdf.

Thiao, D., Leport, J., Ndiaye, B., Mbaye, A., 2018. Need for adaptive solutions to food vulnerability induced by fish scarcity and unaffordability in Senegal. Aquat. Living Resour. 31 (25), http://dx.doi.org/10.1051/alr/2018009.

Trading Economics, 2019. Namibia unemployment rate, viewed 04 2020, from https://tradingeconomics.com/namibia/unemployment-rate.

Trondsen, T., Scholderer, J., Lund, E., Eggen, A.E., 2003. Perceived barriers to consumption of fish among norwegian women. Appetite 41, 301-314.

UNDP, United Nations Development Programme (UNDP), 2019. Human Development Reports. (http://hdr.undp.org/en/countries/profiles/).
United Nations Development Programme (UNDP), 2016. Sustainable development goals. www.undp.org/content/undp/en/home/sustainabledevelopmentgoals.

UNSD, 2019. UN Data: A world of information. Retrieved from http://data.un. org/en/iso/na.html.

USDA, 2015. 2015-2020 Dietary Guidelines for Americans, 8th edn. Available at http://health.gov/dietaryguidelines/2015/guidelines/.

Verbeke, W., Vanhonacker, F., Sioen, I., Camp, J.V., De Henauw, S., 2007. Perceived importance of sustainability and ethics related to fish: A consumer behavior perspective. Ambio 36 (7), 580-585. http://dx.doi.org/10.1579/00447447(2007)36[580:PIOSAE]2.0.CO;2.

WHO, World Health Organisation (WHO), 2014. The Work of WHO in Namibia 2008-2013. Windhoek, Namibia. 